\title{
Resignificar la psicoterapia en el cáncer. Ser para morir: caos, resiliencia y creatividad
}

\author{
Resignify psychotherapy in cancer. Being to die: chaos, \\ resilience and creativity
}

Psikoterapia minbizian esan nahi berrizatea.Hiltzeko izatea: kaosa, erresilientzia eta sormena

\section{Mikel Garcia Garcia*}

*Médico. Psicólogo. Psicoanalista junguiano. Ha trabajado en salud pública de Navarra como médico rural y como psicólogo clínico. Colaborado con ONGs. Miembro de la Sociedad Internacional para el desarrollo del Psicoanálisis. Junguiano (SIDPaJ). Cursando doctorado en “Estudios Internacionales de Paz, Conflictos y Desarrollo” en la Universitat Jaume I (UJI Castellón). Contacto: iratxomik@gmail.com 607110277 


\begin{tabular}{|c|c|}
\hline & 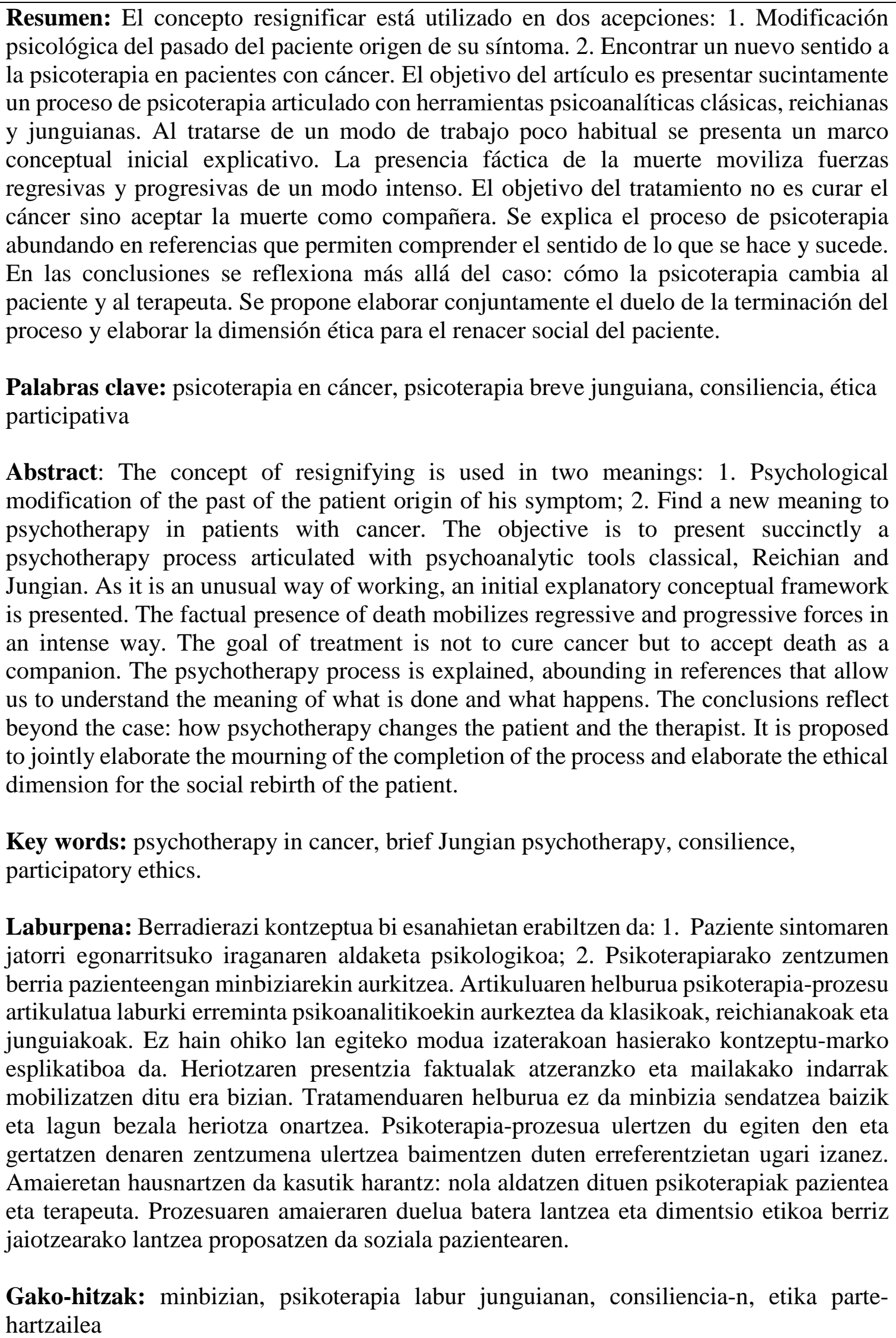 \\
\hline
\end{tabular}




\section{Marco conceptual}

El problema del desconocimiento es central en la teoría y en la práctica del psicoanálisis. Burke (1969) caracteriza la teoría de Freud como una "variante secular de la teología negativa”. Una de las razones por las que el psicoanálisis como ciencia lucha con problemas epistemológicos es que su materia -el inconsciente- es constituida en términos de negatividad. ¿Qué otra ciencia investiga algo que está definido por el prefijo “in”? ?

Los teóricos de la dialéctica subrayan la pertinencia de un proceso de distanciamiento que llaman "el momento negativo". La función negativa -o apofática- consiste en poner en evidencia la inadecuación esencial de nuestras representaciones y de nuestros enunciados con relación al misterio. La palabra griega «apophasis» significa a la vez declaración y negación.

Distancia, hermenéutica y epistemológica respecto a los sistemas anteriores, que relativiza las "verdades" de unos y otros procurando un nuevo acceso a la "Verdad".

Mi enfoque epistemológico es el psicoanálisis junguiano como se desarrolla en la Sociedad Internacional para el Psicoanálisis Junguiano (SIDPaJ) ${ }^{1}$, que extiende el concepto de inconsciente personal incorporando el inconsciente colectivo, enfatizando el simbolismo, la imagen y la información arquetípica. La dinámica que se produce entre las figuras parentales y la información arquetípica determinan y condicionan el desarrollo y la estructuración del sujeto.

En el setting analítico la actitud del terapeuta la defino como "actitud conceptual-relacional consiliente operativa”.

\begin{tabular}{|c|}
\hline $\begin{array}{l}\text { Setting analítico } \\
\text { AC-RCO actitud conceptual-relacional consiliente operativa } \\
\text { Trabajo de complejidad. Caos y creatividad }\end{array}$ \\
\hline Empuje del las figuras del inconsciente colectivo \\
\hline $\begin{array}{l}\text { Función trascendente } \quad \text { Tensión opuestos } \\
\qquad \begin{array}{c}\text { Yo }- \text { si mismo } \\
\text { Sincronía } \quad \text { Bifurcación. Caos-Orden implicado }\end{array}\end{array}$ \\
\hline Función finalista TELEOLOGICA ¿versus causal? \\
\hline $\begin{array}{l}\text { Conflicto: Fractal. Síntoma-Estructura } \\
\text { Holismo: Circularidad versus linealidad }\end{array}$ \\
\hline Factor prospectivo. Aliado en el proceso. \\
\hline $\begin{array}{l}\text { Desfocalizador del conflicto vinculado solo a la historia personal. Complejo. } \\
\text { Arquetipo. }\end{array}$ \\
\hline Antiidealizaciones. El destino del yo es entregarse al misterio. \\
\hline
\end{tabular}

Figura 1. Setting analítico

\footnotetext{
${ }^{1}$ ¿Qué es el psicoanálisis junguiano? Similar a la concepción del psicoanálisis freudiano consiste en escuchar el material que procede del inconsciente, en este caso del colectivo. También es confluyente la idea de que el objeto del tratamiento no es la cura. A diferencia del psicoanálisis freudiano la investigación del material la realiza principalmente el paciente. El terapeuta no interpreta, sino que orienta hacia la asociación y amplificación del material manteniendo la tensión entre "opuestos" para que se produzca un salto creativo y una colaboración entre el yo y el sí-mismo. El trabajo va más allá del sujeto individual ya que no solo le mantiene en un camino de individuación, sino que conduce a un cambio en el material del inconsciente colectivo. El análisis es interminable. Antes de poder hacer un psicoanálisis junguiano el paciente tiene que tener un yo suficientemente estructurado y para lograrlo puede que tenga que hacer un trabajo de psicoterapia junguiana que le permita elaborar buena parte del material del inconsciente personal. Empezar un proceso de psicoterapia o psicoanálisis junguiano es una decisión inicial que dependerá del diagnóstico estructural del paciente, y de las condiciones de analizabilidad (Castillo, 2017).
} 
Esto significa que hay un trabajo de complejidad en el que el caos y la creatividad son referentes que acompañan permanentemente el proceso. Este se caracteriza por dos elementos fundamentales que lo diferencian de la posición psicoanalítica clásica. El primero es que las figuras o imágenes arquetípicas del inconsciente colectivo empujan el proceso. Fenómeno distinto del modelo hidráulico freudiano para el que la emergencia en la conciencia del material del inconsciente personal es el resultado de dos fuerzas antagónicas; las defensas que mantienen esa información reprimida y el empuje de las mismas. Las informaciones del inconsciente colectivo no resultan de un proceso dinámico de represión, sino que son constitutivas del sujeto, heredadas. Originadas en los dinamismos antropológicos de las generaciones precedentes incluso prehumanas, han quedado depositadas en el inconsciente colectivo a modo de "arquetipos”. El segundo es la función finalistao teleológica que significa que hay una "intencionalidad" de los arquetipos para el desarrollo del sujeto. La función finalista no es antitética de la causalidad. Un conflicto libidinal en la infancia deja una marca compleja con un material reprimido, unas defensas y unos dinamismos. Esto instaura un "fractal" o "atractor" que orienta el desarrollo posterior del sujeto. Como apunta Grof (1994a, 1994b), un conflicto perinatal condiciona el desarrollo de las siguientes fases libidinales en un área determinada. La "marca resultado” puede ser un síntoma y el conjunto de síntomas junto con el resto de dinamismos del sujeto configuran un "todo particular” que es una estructura concreta distinta de la de cualquier otro sujeto, aunque podamos diagnosticar tipologías de estructuras que requieren herramientas terapéuticas diferenciadas: psicótica, borderline; neurótica. La estructura es un sistema particular en el que los dinamismos de sus partes constituyentes la convierten en abierta o cerrada.

En el setting analítico la estructura del paciente se va a ir transformando mediante los procesos relacionales que se instauran en la relación paciente terapeuta. Jung detecta un mecanismo irracional del inconsciente colectivo que llama "función trascendente" (Jung, 2004) que es una expresión de la función teleológica y mediante la cual, al modo de la dialéctica, se intenta unificar los opuestos.

La relación entre lo consciente y lo inconsciente, lo conocido y lo desconocido, sólo puede resolverse por un factor irracional. En la práctica, los opuestos pueden unirse sólo en forma de compromiso, o irracionalmente, de algo nuevo que surja entre ellos que, aunque diferente de ambos, sin embargo, tiene el poder de tomar s u s energías en igual medida como una expresión de ambos y de ninguno de los dos. Tal expresión no puede ser concebida por la razón, sólo puede crearse a través de la vida.

Salomón usa el concepto de la función trascendente para apoyar una relación de objetos, y posiblemente biológica, de la psicología analítica. Salman se opone a Salomón señalando que:

Aunque la función trascendente tiene un movimiento dialéctico, es un "opus contra naturam", que involucra cualidades de participación del ego que la separan de los procesos de desarrollo y dialécticos instintivos ... la función trascendente va más allá de la dialéctica en el diálogo consciente introduciendo la creatividad, el sufrimiento y la integridad ética a la interacción de los opuestos. Estas adiciones actúan como el fermento alquímico que transforma el proceso dialéctico (Salman, 1993, p. 143).

La función trascendente no sólo trata de unificar consciente e inconsciente del paciente mediante diversos fenómenos (material onírico, síntomas, sincronías) sino que en el setting analítico incluye al analista de modo que es un factor que facilita los procesos de "transferencia"2 y “contratransferencia”.

La información movilizada connota el proceso de una circularidad (mandala) que trasciende

\footnotetext{
2 El término transfert de Huckel fue tomado por Freud para la "transferencia de cargas de una parte del cuerpo a otra". Será C. G. Jung quien, ante el hecho incontestable de la transferencia, plantee a Freud la necesidad de que todo analista estuviese a su vez analizado, siendo por tanto el primero en introducirlo, tal y como él mismo lo contempla: «Reconociendo estos hechos, el propio Freud aceptó mi exigencia de que el médico seaanalizado».
} 
la linealidad, aunque entre ciertas partes de la estructura y, en ciertos momentos, la relación entre ellas sea lineal o causal.

Habrá dinamismos en los que será preciso un análisis causal reductivo de las relaciones entre partes del sistema, y, en estos casos, la dinámica del análisis de las resistencias es fundamental no sólo para disolver un fractal sino para preparar al sujeto para la profundización del análisis y la adquisición de un estilo auto analítico. Pero el proceso en general puede ser contemplado como complejo y caótico, condiciones para que primero se deconstruya la estructura y posteriormente pueda transformarse. Mantener la tensión del caos es otra aportación junguiana, que evita cerrar en falso (interpretaciones no mutativas ${ }^{3}$ ) las potencialidades de cambio. En este paradigma se profundiza en el caos amplificando los materiales, asociándolos con otros, creando conectores entre partes. Se hace un trabajo temprano de los fenómenos transferenciales mediante amplificación: paratransferencia. Este modo de trabajo requiere una cierta preparación del sujeto para que en pueda soportar la tensión.

En el setting junguiano está presente una confianza en el abandonarse al misterio, con prudencia, sin control del misterio. Ya que por esta actitud podrán surgir momentos de bifurcación del caos en los que una nueva significación se hará consciente. Los insight son momentos de "experiencia cumbre" en los que la conciencia experimenta un estado dialógico, de comprensión directa e intuitiva, de certeza en que esa comprensión es "verdadera", de confianza, de beatitud, se podría hablar que son momentos "místicos" o numinosos.

En los procesos terapéuticos paciente y terapeuta, no sólo el paciente, pueden transformarse en el proceso relacional que se establece entre ellos.

\section{Un paciente con cáncer.}

Varón 60 años, acude derivado por una expaciente que estaba en psicoterapia con otro terapeuta y que traté médicamente de un linfoma de Hodking coordinado con su terapeuta.

"Me han diagnosticado, hace 15 días, de un cuadro grave: adenocarcinoma pulmonar con metástasis".

Atlético, calvicie fronto-temporal marcada, bigote copioso y bien cuidado, se mueve con agilidad, resolución e hiperesfuerzo masculino en el estar, especialmente en el apretón de manos. Voz modulada, armoniosa, con timbre de tenor. Verbaliza su discurso con emociones coherentes. Conecta con la mirada conmigo y explora el espacio. La mandíbula inferior es afilada y desviada hacia la izquierda. Se aprecia contención muscular, una actitud pasivo-femenina, una tendencia a la minuciosidad, exactitud y perfección de los detalles.

Buen sentido de la realidad, y responde, a señalamientos de prueba, con la producción de nuevo material clínico o asociaciones confirmatorias.

Fumador de dos paquetes diarios desde la adolescencia. Tercero de cuatro varones, nació a los 10 meses. Lactancia materna de dos años. Destete brusco. Broncas entre los padres. Padre de genio muy violento, “pero un corazón de oro”, incapaz de garantizar la economía familiar. Madre primaria, ignorante, con mucha fuerza-agresividad. Al padre le tenía miedo y la relación con la madre la describe como de deprivación afectiva, "nunca me ha apoyado". Pesadillas, en especial de matar al padre por la violencia contra la madre. Ambiente religioso, pecado.

Enamoramiento platónico de un compañero. Masturbación con mucha culpabilidad. Adolescencia en seminario, que deja a los 19 creyéndose un filósofo pues había estudiado mucho. Miedo al atrapamiento afectivo por la mujer. Fetichismo con el pie: le es necesario para excitarse y para abandonarse al contacto sexual con una mujer ("si se cuida bien los pies seguro que también la vagina y no hay peligro de suciedad-contagio”). Eyaculación precoz. Promiscuidad. Eritrofobia al no atacar a los homosexuales cuando otros amigos lo hacían. La muerte accidental del padre le resultó bastante traumática y le sorprendió esta respuesta.

Se hizo cargo de la madre conviviendo con ella al ser el único soltero de los hermanos. Tenía

\footnotetext{
${ }^{3}$ Strachey (1976) llama interpretación mutativa a la que produce cambios estructurales.
} 
un piso al que iba mucho para su vida privada, paro no se mudaba por culpa de dejarla sola y porque, a cambio, la madre le cuidaba. Desarrolla síntomas hipocondríacos, tras un conflicto con su jefe, acude a un psiquiatra, y toma Deanxit del que desarrolló una dependencia psicológica. Se casó con una mujer que le dejaba bastante libre para sus relaciones con amigos y sus aventuras. Dos hijos y un nieto de 6 años. Se jubiló hacia tres años, por cierre de la empresa. Situación que vivió bien entre otras cosas para cuidar a su nieto con el que tiene un afecto especial. Un accidente del nieto, seis meses antes, le afectó mucho. A los cuatro meses de ese accidente empeoró su bronquitis crónica a partir de lo cual fue diagnosticado.

El paciente demanda tratamiento médico que complemente el de quimioterapia que ha decidido hacer y un apoyo emocional porque se le han despertado unos temores hipocondríacos que le desbordan, un sentimiento de que lo que le sucede es por su "culpa”, y mucha ansiedad. El cáncer lo atribuye a ser fumador de dos paquetes diarios desde la adolescencia.

Su amiga derivante le habló del beneficio de tratamientos médicos alternativos como complemento a la medicina oncológica. Y ella también le indicó que en su caso ella tenía un terapeuta ya que él podría necesitar también un trabajo psicológico.

Para el diagnóstico, además de la entrevista con una perspectiva integradora de diversas herramientas psicoanalíticas, reichianas, junguianas. Empleé test psicométricos (MCMI III Millon) y proyectivos (Test Relaciones Objetales Phillipson), que además de proporcionar información servían para ir creando un vínculo de alianza de trabajo.

\section{Lo destacado del diagnóstico:}

Adenocarcinoma pulmón IV.

Estructura psiconeurótica:

1. Compulsivo, pasivo-femenino. Componentes reactivos fálico-narcisistas.

2. Tensión ocular. Tensión cervical. Bloqueo diafragmático. Bloqueo abdominal (Navarro, 1993).

3. Pensante extrovertido. Sus reflexiones no le servían para solucionar problemas sino para rumiar.

4. Complejos negativos paterno y materno (Jung, 1994).

Homosexualidad latente. Derivada de una no salida de lo materno más que de una regresión por represión paterna. Defensa anal para seducir al padre y bloquear su violencia.

Hipocondría

Dependencia psicofármacos.

Daltónico.

Adecuada capacidad simbólica.

Ganas de vivir, de curarse del cáncer.

\section{Tratamiento}

Es importante poder llegar a formular una hipótesis psicodinámica que explique el cáncer como síntoma psicosomático. Entendido en función de los dinamismos que se hayan movilizado en su estructura y que relacionan la situación actual, los desencadenantes actuales, la movilización del material reprimido en el consciente que se le puede activar por los desencadenantes y los dinamismos que finalmente han producido el síntoma.

Si es posible formular una hipótesis psicodinámica suficientemente plausible se puede iniciar un trabajo analítico que en los casos de cáncer requiere integrar muchas dimensiones.

La hipótesis es la primera condición, además hay que evaluar otros criterios de analizabilidad 
y las condiciones objetivas del sujeto. Especialmente su nivel energético para soportar un trabajo movilizador tanto por la devastación orgánica por las células tumorales como por los tratamientos médicos que agreden al conjunto de las células del biosistema además de las tumorales.

Es fundamental que el terapeuta tenga claro que va a poderse hacer cargo del tratamiento que es bastante movilizador. El fantasma de la muerte no es sólo simbólico, como en todos los casos de psicoterapia, sino real en el caso del cáncer.

Sin embargo, y precisamente por esta facticidad real, hay una movilización más acelerada de los procesos dinámicos psíquicos y, eso, se convierte en un aliado terapéutico. El caos en el setting es mayor que en otros casos pues está presente todo lo extra sistémico: los tratamientos médicos, las ansiedades del sistema familiar y las respuestas de los sanitarios.

Becker (2003), iniciador de la teoría de la Gestión del Terror (TMT), señala que nuestras acciones están encaminadas a evitar o ignorar la inevitabilidad de la muerte puesto que la ansiedad resultante de esa conciencia de finitud podría llegar a ser potencialmente paralizante. El mecanismo para controlar los pensamientos de muerte se basa en dos tipos de defensas. Las defensas proximales se activan cuando los pensamientos de muerte se encuentran en la conciencia principalmente a través de la distracción, es decir, fijando la atención en otras cosas y reduciendo la atención focalizada en uno mismo, incluso trivializando la propia vulnerabilidad ante la muerte (Pyszczynski, Greenberg \& Solomon. 1999 y Arndt, Cook \& Routledge, 2004) normalmente con pensamientos conscientes sobre nuestro excelente estado de salud o la tendencia de nuestra familia a la longevidad (Pyszczynski et al., 1999). En este momento, los pensamientos de muerte quedan fuera de la conciencia pero aún son muy accesibles. Es entonces cuando se activan las defensas distales (visión cultural del mundo y autoestima) que básicamente intentan asegurar la permanencia de esos pensamientos de muerte alejados de la conciencia. El ser humano trata de dar un sentido a su existencia para proporcionarle una inmortalidad simbólica que pueda ayudarle en la aceptación de su finitud (Florian \& Mikulincer, 1998).

En la perspectiva junguiana es importante evaluar en el diagnóstico el nivel de activación del arquetipo del sanador herido ${ }^{4}$. Mientras estábamos en el proceso diagnóstico me vino la imagen de un niño de cinco años que traté con cáncer y que murió. Mi conexión con ese material se produjo cuando me informó de la especial relación que tenía con su nieto y de su sufrimiento cuando tuvo un accidente por el que pudo morir.

Yo estaba herido por la muerte del niño que traté. La dinámica del arquetipo es distinta que una dinámica de culpabilidad. No me sentía culpable por la muerte de mi paciente y no tenía nada que reparar. Si estaba herido y esa herida era un dinamizador para mis actitudes sanadoras. Esta activación facilita una mayor empatía con la herida del paciente por su enfermedad y frena actitudes omnipotente-salvíficas hacia el paciente. Ser consciente de las activaciones arquetípicas es muy útil para entender también la vehiculización del material en la trasferencia y los dinamismos defensivos. Un paciente en una situación dramática, que requiere muchos cuidados, activa su complejo y espera que el terapeuta sea una madre omnipotente de la que depender para resolverle el conflicto.

\footnotetext{
${ }^{4}$ C. G. Jung, conceptualiza el mito del centauro Quirón en el arquetipo del sanador herido, en él, nos dice que todo psicólogo y/o sanador es también un paciente. En la sanación hay una oportunidad de mayor integración de dimensiones.
} 


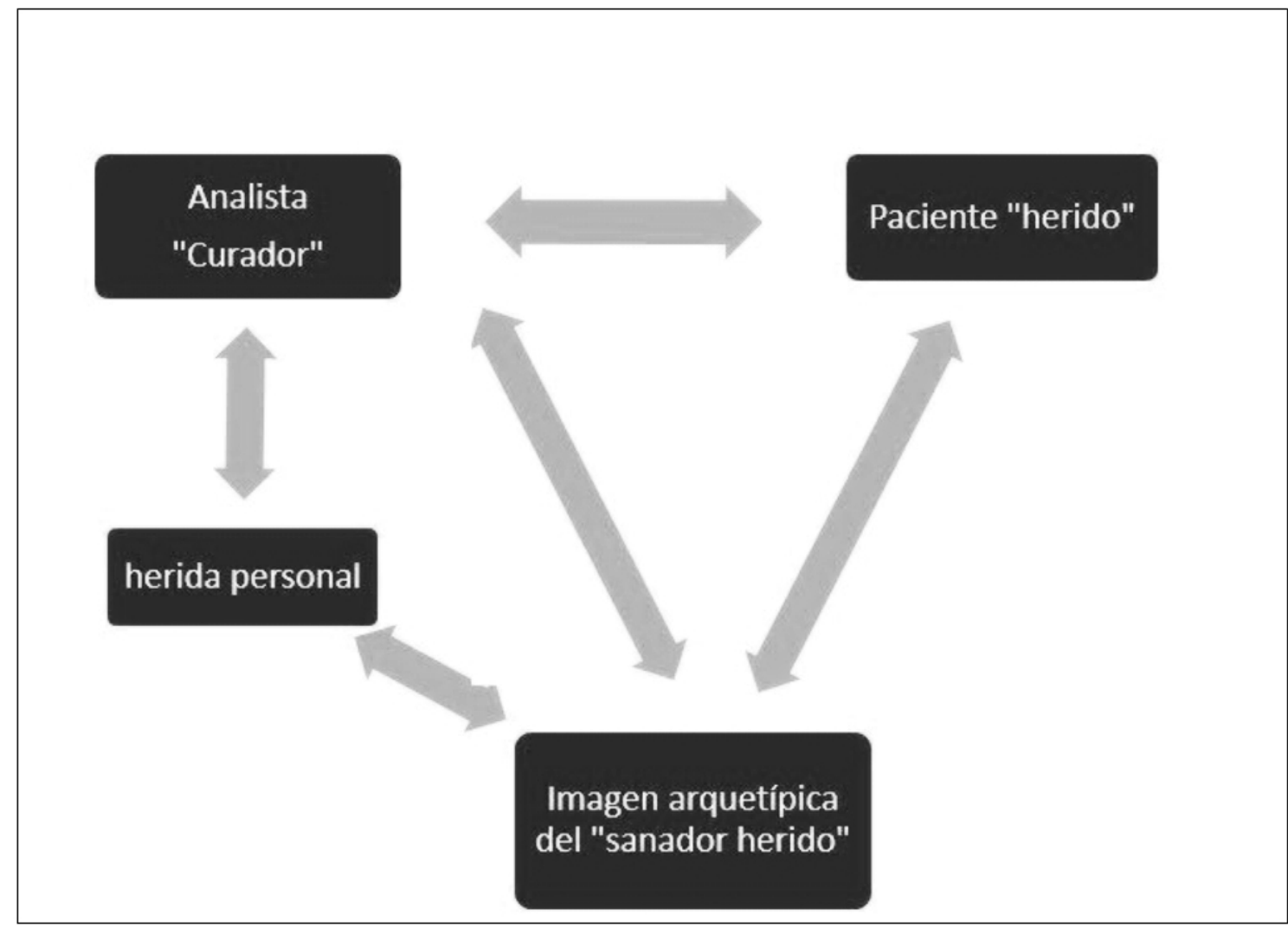

Figura 2. Dinamismos del sanador herido entre paciente y terapeuta

La propuesta fue un tratamiento de psicoterapia breve junguiana.

- Objetivos: Mejorar su calidad de vida, centrándonos en la elaboración de un conflicto clave: su culpabilidad y temor al castigo. Que pudiera morir con dignidad y, eventualmente curar su cáncer.

- Duración: nueve meses si no moría antes.

- Frecuencia: Trataríamos de vernos una vez a la semana, en la consulta o en el hospital si era ingresado.

- Estaríamos en contacto telefónico cuando lo necesitara. Podría traerme materiales suyos notas, reflexiones, sueños, dibujos...

- Seguiría un tratamiento dietético, y ortomolecular para elevar la vitalidad de su sistema inmunitario, paliar los efectos de la quimioterapia en las células sanas, y actuar, sinérgicamente con la quimioterapia, contra las células cancerosas tanto modificando el terreno biológico para hacerlo incompatible a estas como atacándolas directamente. Se implementaría un trabajo con energía orgónica para incrementar su nivel vital (Reich, 1942).

- Herramientas: Psicoanalíticas, reichianas, junguianas, orgánicas, cuerpo.

El trabajo con el cuerpo es muy interesante en los cuadros psicosomáticos. Era la vía de entrada. El paciente percibía su cuerpo como un espacio de culpa y peligro.

“... a la civilización occidental le resulta difícil honrar la dignidad del cuerpo y la diversidad de los cuerpos humanos" (Sennet, 1997, p. 17). Durante muchos siglos el cuerpo ha sido estigmatizado fundamentándose en la visión negativa platónica expuesta en el Fedón que el cuerpo es una prisión para el alma (sõma semã). Esto se reforzó por la antropología cristiana, para la cual, el cuerpo era sinónimo de pecado y a través del cual el hombre sólo podía aspirar a estados y valores 
negativos. El cuerpo simbólico reeduca algo substancialmente diferente a lo que estudia Foucault en su libro Vigilar y Castigar (1976), cuando se refiere a un poder que mide, califica, jerarquiza y desprecia, los anulados y tutelados cuerpos de los educandos. Hablar de educar desde el cuerpo permite examinar aspectos como la feminización y la masculinización del cuerpo y la cosificación del cuerpo político.

Las herramientas reichianas de psicoterapia corporal (Navarro, 1998), las iba a modificar bajo el referente conceptual de las consideraciones junguianas que resignifican el cuerpo.

El cuerpo es un vasum hermeticum. El propio síntoma del cáncer es una vía para que el paciente pueda conectar con un mensaje del inconsciente para que se modifiquen actitudes, modos de estar en la vida consciente, que si no se modifican van a conducir a la muerte del sujeto.

El síntoma muchas veces es una manifestación en la realidad física de lo que el paciente no está realizando en su psique, una consecución de la acción de la función trascendente mediante una sincronicidad (Jung, 1990). Por ello, el cuerpo es una vía preferente de entrada al trabajo psicoterapéutico en los casos psicosomáticos.

“... Con la sincronicidad como punto de partida, es posible empezar la construcción de un puente que atraviese los mundos de la mente y de la materia, de la física y de la psique.” (Peat, 1988, p. 10).

El cuerpo proporciona límites a la personalidad y es un envoltorio de piel, que delimita lo que se acepta y lo que se rechaza y que constituye la sombra ${ }^{5}$ (Jung, 2001).

“... el cuerpo es necesario si se pretende que el inconsciente no tenga efectos destructivos sobre la consciencia del ego, porque es el cuerpo lo que proporciona límites a la personalidad” (Jung, 1993, p. 291).

En “La personalidad velada”, Abac (2008) escribe “... ¿ ¿Será que el cuerpo físico está expresando la falta de cuerpo psíquico? [...] ya que el Self puede también manifestarse en el cuerpo... impulsando al ego a la transformación. [...] Los síntomas son imágenes cautivas en la forma física del cuerpo" (Abac, 2008, pp. 62-63).

El setting contaba con un diván reichiano para poder realizar ciertos actings ${ }^{6}$ con el paciente tumbado y verbalizar lo vivido después de la realización de la acción.

El marco inicial era de un maternaje estructurante que le diera soporte para atender los tratamientos del cáncer y para la confrontación que iba a ser necesaria, a la vez que se realiza un análisis de resistencias y una cierta función castrante respecto a sus funciones principales.

\section{Secuencia esquemática del trabajo. \\ Primera etapa.}

Recoger, escuchar el material sin interpretarlo, facilitar la asociación y amplificación, facilitar la canalización de la contención emocional, transmutar la rabia contenida en agresividad para afirmar la existencia y abandonar el cáncer.

Voy a presentar el trabajo en modo de secuencia dinámica (Ver Figura 3).

El acting "del pez" consiste en que el sujeto vaya mirando alternativamente un punto en el

\footnotetext{
${ }^{5}$ Término de Jung que se refiere a los rasgos y actitudes que el yo no acepta como propios y habitualmente proyecta en otro objeto: otros sujetos, el propio cuerpo... Sería el "lado oscuro" del yo y del sí-mismo. La sombra es amoral; ni buena ni mala. No es equivalente a material reprimido ya que también se rechazan actitudes o capacidades. Estas últimas aportan creatividad cuando se realiza en trabajo de integrar la sombra en la conciencia.

${ }^{6}$ Los "actings" son movimientos neuromusculares con una vinculación funcional, neurovegetativa, a momentos históricos en los que dichos movimientos jugaban una función somatopsicológica espontánea y natural. Si, en su momento, fue impedida, castigada, o frustrada dicha función, la emoción fue anclada en la memoria muscular, y al hacer el "acting", en el espacio terapéutico permisivo, esta emoción reprimida puede liberarse apareciendo el recuerdo o material vinculado al momento histórico de represión lo que conduce a una abreacción neuromuscular, insight y elaboración psíquica mediante la verbalización posterior. Mediante la acción neuromuscular y en la relación objetal con el terapeuta podemos ir reproduciendo la historia del sujeto.
} 
techo y la punta de su nariz mientras que con los labios hace un movimiento alternativo de proyectarlos como un cilindro y recogerlos. Es conveniente que respire por la boca. Después de un tiempo de realizarlo, alrededor de 15 minutos, se pide que pare y que verbalice lo vivido.

Con una indicación de que lo que comunique no puede hacerlo desde su lógica pensante sino desde la sensación y la emoción. Con este modo, se intenta activar su complejo paterno negativo y de desarrollar la función inferior que desde el punto de vista junguiano es la más inconsciente y la que facilita más el acceso al material profundo, que es este paciente era el sentir.

\section{Secuencia dinámica}

- Acting "pez" en contexto de frustrar función superior.

Función inferior + cerca de totalidad del inconsciente

Activación complejos (-) materno paterno

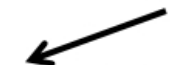

Fantasía "Ser devorado". Fantasía inconsciente.

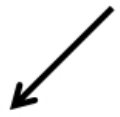

En extrovertido, el inconsciente aparece a menudo como una fantasía

Fantasia inconsciente del cáncer (Chiozas)

Sueño Cíclope Unificación mirada. Ve una luz. Realidad simbólica accesible

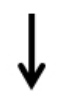

Acting "boca abierta" Imagen huérfano.

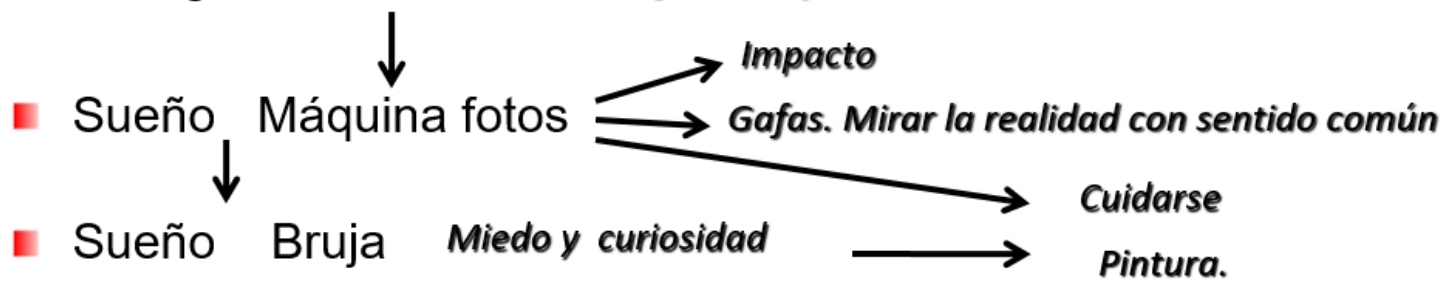

Selección del material. Se deja sin elaborar el material arquetipico

Figura 3. Secuencia de eventos significativos en la primera etapa

En una ocasión mientras hacía el acting tuvo una fantasía de ser devorado:

"Me siento un muy pequeño, un plancton, pasando por una hilera de dientes estáticos que me cortan como cuchillas hasta verme en el interior de un animal. Sentía el movimiento de paso, el dolor de ser herido y el miedo a morir”.

Lo asociaba con las barbas de las ballenas que filtran sin morder. La fantasía le conducía a la convicción que ese era el modo como sus células tumorales mataban a sus células sanas, absorbiéndolas y troceándolas con líquidos corrosivos. Así crecía el cáncer y eso era lo que lo podía matar realmente. Le llamaba la atención que en la fantasía se veía en el interior del animal, lo que significaba que aun siendo un pasaje doloroso aún no estaba muerto. Lo asocio a su temor de que su cuerpo muerto fuera devorado por los gusanos. Temor por el que estaba decidido a la incineración.

Leyó mitos en los que sujetos humanos son tragados y devueltos tras un período y empezó a comprender el significado del pasaje muerte renacimiento.

Recordé a Chiozas (1989) en su afirmación de que en los pacientes con cáncer se encuentran fantasías inconscientes y entendí que esta fantasía era muy importante para el paciente. En este 
momento se analizó parcialmente, a la espera del momento para utilizar esta información de una manera pragmática en algún trabajo.

Tuvo un sueño, “el cíclope”:

"Un amigo me enseña su primera nieta. La miro más de cerca y veo que sólo tiene un ojo, es un cíclope. El ojo está en el centro de la frente es muy grande, ocupa mucho espacio, lo visualizo de una forma muy sensorial es atractivo de color marrón, es bello. Me preocupa lo que pasará con la tridimensionalidad y la profundidad de campo. Es un ojo muy funcional y puede ver perfectamente todo. Tiene una capacidad de movimiento realmente asombroso. Realmente creo que con ese ojo tan grande, plástico y movible no necesitar tener dos ojos su belleza y capacidad que va más allá de la de dos ojos.”.

Inicialmente está preocupado por la “pérdida de la tridimensionalidad” por tener un solo ojo. Sin embargo, le atrae la belleza.

El trabajo de amplificación fue consolidando su capacidad de unificar la mirada y acceder a la realidad simbólica.

Realizando el acting de "boca abierta" en la que están mirando un punto del techo teniendo la boca abierta, visualizó una imagen de ser un huérfano. La imagen se acompañaba de tristeza, y con el sentimiento de haber sido abandonado. Recordaba escenas concretas cuando tenía 12 años que conectaban con ese sentimiento de abandono y soledad.

Al poco tiempo tuvo un sueño que le impactó mucho el de la "máquina de fotos”:

"Estoy retratando a gente con una máquina de fotos. El ambiente es antiguo. Lo curioso es que veo a la gente en la realidad como si fueran imágenes en movimiento con la textura de un negativo. Distingo el granulado químico de soporte del celuloide. La imagen es borrosa, poco definida, poco enfocada. Los personajes son mujeres. Voy ajustando los controles de la máquina y lo que veo en la realidad va variando. Yo miro directamente la realidad no miro a través del visor de la máquina. Estoy asombrado y quiero acabar de ver bien con nitidez. Al final lo consigo al mover los controles de la máquina. Me sorprende que las imágenes sean en blanco y negro. Son varios personajes en un ambiente poco iluminado, que podría ser un interior. Hay un personaje más central lo enfoco y es una mujer con el pelo claro. Soy consciente de la relación entre la máquina y la realidad y me gusta el blanco y negro. Es como si eso representa la realidad de modo más esencial más profundo más íntimo. Como si fuera captada en su Aletheia. Estoy contento de estos descubrimientos”.

Una relación indirecta con la realidad a través de la tecnología de la máquina de fotos que le lleva a querer conectar con lo esencial directamente y encuentra que el "blanco y negro" representa el nivel más profundo de lo real. Le resulta gratificante ese descubrimiento en el que además el personaje central de la realidad es una mujer con el pelo claro. Reconocía que aún necesitaba “gafas” para mirar la realidad pero que su "sentido común” estaba consolidándose. La intensidad de sus sentimientos depresivos disminuyó mucho.

Tuvo un sueño. "La bruja":

"He acudido a una bruja porque no sé lo que tengo que hacer, tampoco se para que he acudido a la bruja ni cuál es mi objetivo, pero estoy con ella. La bruja es un personaje medio irónico o muy malvado. Tengo la certeza de que sabe mucho, es una bruja vasca, es como si tuviera mucho que ver con mi antepasado. Realmente no me dice nada, ni siquiera habla, sólo me mira de una forma que me produce temor. Me voy de su lado porque me abruma, pero a la vez sé que pierdo la oportunidad de enterarme de cosas que pudieran ser importantes. Tendría que volver de otra forma en la que pudiera comunicarme con ella”.

Es un personaje al que acude sin saber por qué, pero reconoce que tiene que ver mucho con su antepasado y que es un ser sabio y malévolo. Tiene miedo y se aleja de la escena, aunque 
reconoce que se está perdiendo algo y que tendrá que volver para enterarse de cosas importantes.

La elaboración del sueño le llevó a la convicción de la necesidad de cuidarse y protegerse mejor. Su miedo ante el personaje lo asociaba con la fantasía de ser devorado-aniquilado. Pero también tenía curiosidad por el mensaje y lo mismo que en la fantasía de ser devorado finalmente no moría e intuía que podría relacionarse con personaje sin morir. Decidió acercarse a la "bruja” mediante el dibujo como una herramienta para ir tolerando mejor la relación con ese personaje porque empezaba a desear conocer su mensaje.

Todos estos materiales que han ido apareciendo se trabajan de un modo selectivo y focalizado para los objetivos de la psicoterapia breve.

Si se estuviese de trabajando desde la perspectiva de un psicoanálisis junguiano serían trabajados los componentes de los materiales que pueden estar conectados con información arquetípica. La mujer focalizada en el sueño de la máquina de fotos, podría representar el arquetipo del ánima (el aspecto femenino presente en el inconsciente personal de los hombres), la bruja (el poder destructivo de la naturaleza, lo inesperado de la misma, lo desconocido y misterioso, son también cualidades del arquetipo de la madre). El paciente recordó La Escena de brujas de Goya (1798) que muestra también ese aspecto de la mujer mayor, aliada de lo oculto, que seduce, tienta y daña al inocente.

Indiqué el acting “de morder un trapo” mientras rotaba los ojos fijándose en que lo que iba viendo con la mirada y mordiendo sólo cuando veía al terapeuta. Me había colocado en su campo visual derecho. Después de varias veces de realizarlo empezó a sentir bastante dolor dental. Le era muy desagradable y le irradiaba hasta la zona occipital. Era intenso y quería dejar de hacer el acting. El dolor era una defensa para impedir el contacto con la rabia inconsciente hacia la figura paterna. Se podía haber hecho un trabajo reichiano de análisis de resistencias e insistir en el acting para provocar una descarga abreactiva de la tensión que le provocaba dolor tratando de que hubiera una conexión con el origen histórico de la rabia.

Sin embargo, era oportuno impedir la descarga de la rabia, para activar algún polo opuesto. El fundamento de esto es el principio junguiano de que manteniendo la tensión de opuestos se activa la función autorregulatoria de la psique y se dinamizan los contenidos. Presentándose materiales oníricos, recuerdos históricos, sincronías.

Pasado un tiempo propuse un trabajo de imaginación activa (Von Franz, 1989) con la intención de transmutar la rabia en agresividad. Es un planteamiento alquímico que trabaja con la materia (libido no descargada catárticamente) para un cambio psíquico (Jung, 2005; Von Franz, 1991). El trabajo concreto lo planificamos entre los dos, y que hizo a diario. Ese trabajo lo hacía sólo en su casa una vez al día en un ambiente tranquilo, sin estímulos. Se iba modificando en función de lo que fuese aconteciendo. Finalmente fueron tres fases. En cada fase yo le sugería la situación de partida inicial.

En la primera fase el analizando se iba a imaginar una escena en la que dialogaba con las células cancerosas, con una actitud de escucha a las células cancerosas, estando atento a las imágenes, recuerdos, emociones o ideas que le surgiesen tanto durante el tiempo de la imaginación activa o posteriormente en la conciencia de vigilia o en los sueños.

Para la segunda fase el punto de partida era un diálogo con sus células cancerosas dándoles permiso para que murieran afirmando que ya había entendido su mensaje, que les agradecía su manifestación, y que ya podían morir. En todo esto de tiempo estaba trabajando su propio temor a la muerte, y su "deseo de inmortalidad” como negación a la muerte. La paradoja es que precisamente las células tumorales son biológicamente "inmortales" al estar liberadas de los frenos que tienen las células que participan de un sistema biológico homeostático. Si no aceptaba su muerte, no podían morir sus células tumorales. 
El paciente en este momento empezó a tener sentimientos agresivos de lucha directa contra las células cancerosas “yo os voy ayudar a morir matándoos”, se imaginaba que las atacaba a distancia con flechas que les lanzaba con un arco, una célula tras otra, de una en una. Es importante la fantasía de lucha que le surge: el arquero. Por varias razones. Es una fantasía muy opuesta a la de ser devorado aniquilado por la ballena. Es activa, a distancia, fálica... Supone un fenómeno creativo, innovador en su psiquismo, que ha transmutado la energía de la rabia (pasividad del complejo materno y castración del complejo paterno, activadas en la transferencia terapéutica) en agresividad al servicio de su existencia. Una acción artesana, lenta, una a una las células cancerosas son flechadas. También es importante porque se comprueba como la psique despliega imágenes arquetípicas que no aparecían antes en la conciencia del sujeto y estaban latentes.

Este momento del proceso requería una actitud terapéutica más activa: proporcionando información e interpretando el material. Su imagen de arquero conecta con el mito del "Arco de Philoctetes": "el compasivo con Heracles arquero herido", castigado por romper un pacto de secreto, curado en un sueño y que acabó la guerra de Troya con sus flechas. Le indiqué que leyese el mito y conectó con la peripecia de un héroe que en parte era común. Y, lo más importante, empezó a distanciarse de su drama construyendo un relato mítico de su existencia. Esta capacidad es algo a potenciar en el análisis.

Asentar el proceso heroico como un paso evolutivo llevó un tiempo. Tras el cual era preciso desidentificarse del héroe que siente valor y virtud por el éxito y triunfo que le lleva a una actitud de autocomplacencia narcisística y dependencia del reconocimiento del otro. Más allá del héroe recompensado por la eudoxia de su valía.

Este modo de trabajo sistemático y ordenado con fases preinterpretativas e interpretativas de amplificaciones no reductivas del material. Coincide en parte con Davanloo (1992) aunque la parte de interpretaciones reductivas es menos importante.

La frustración activa es una estrategia compartida por Ferenzci. La frustración activa respecto al uso de su función superior y la frustración derivada del análisis del carácter están presentes siempre, con presión orientada a los sentimientos. Eso incluso en el período inicial del maternaje. Con el punto preciso para que la rabia derivada de la presión "acorralamiento" no conduzca a defensas depresivas sino a catectizar la transferencia y a luchar contra las células cancerosas. La frustración activa se articula con gratificación activa (maternaje). Articulación que es un arte en cada fase con componentes distintas.

En la tercera fase de la imaginación activa el paciente dialogaba con sus células "madre" invitándolas a proliferar y ocupar su dentro del biosistema. Con ello el mismo paciente estaba habitando el templo de su cuerpo.

Con ese trabajo le surgió la duda: ¿Quieren vivir? Y consecuentemente ¿quiero vivir? Estas preguntas marcaron una inflexión en el proceso. La pregunta sobre si realmente quería vivir no le resultaba fácil de contestar. Se da cuenta que había vivido siguiendo la corriente de la propia vida, sorteando sobre ella con algunas distracciones que ahora sentía inadecuadas. A medida que iba decantándose por realmente querer vivir su agresividad contra las células cancerosas era mayor y su implicación en el intento -para que las células madre ocuparan su espacio- también más intensa.

Hay que destacar la radical diferencia respecto a una actitud militarista consonante a la cultura de violencia y paz negativaen la que estamos. Es frecuente plantear en los casos de cáncer que el paciente tiene que luchar a muerte con su enemigo: el cáncer. A veces les surge espontáneamente y en otras son empujados por sanitarios, familiares o terapeutas. Una visualización desde esa perspectiva sería muy distinta de la planteada en el caso. En muchas ocasiones la expectativa de luchar para vencer al cáncer conduce a un sentimiento de culpa ya que los sujetos no se sienten capaces de lograrlo. Situaciones que "retraumatizan” a los sujetos. Que desconocen, además, las 
dinámicas inconscientes de las que el cáncer es una expresión.

Esta tercera fase supone una visualización creativa: Reprogramar las células. Potencia la “fantasía vera” y el pensamiento simbólico.

En potenciar la fantasía hay convergencia con Stekel en este caso mediante la imaginación activa y las simbolizaciones, también en el hincapié en la intuición anticipatoria que en este paciente era una función auxiliar.

Biológicamente el cáncer estaba remitiendo, las metástasis no se detectaban, la recuperación biológica muy clara y su oncólogo, dada la evolución favorable, decidió suspender alguna tanda de la quimio programada.

El paciente era capaz de hablar de su cáncer con su entorno lo que es un ejercicio de resiliencia y autocuración. Había desarrollado la capacidad de comunicar su experiencia de una manera ligera y creativa, más allá del trauma estimulando recursos internos y transformando la afirmación negativa "soy impotente" al positivo "puedo manejarlo “, sin caer en el síndrome de Pollyanna ${ }^{7}$.

Las elaboraciones fueron generando más confianza al paciente en el proceso y empezó la segunda etapa del análisis.

\section{Segunda etapa.}

No voy a extenderme mucho en esta etapa pues el objetivo del artículo es presentar un modo de trabajo que ya está explicitado en la descripción de la primera fase.

En la segunda etapa, hasta el final, el material emergente era objeto de atención y de análisis más exhaustivo. Un análisis caracterial de los aspectos pasivo femeninos, actings indicados para mover material o constelizarlo y tras los que se hacía hincapié en una verbalización centrada en la discriminación perceptiva, trabajo con la transferencia y los sueños.

Dos sueños fueron claves.

"Un anciano, está intentando convencer a un juez para que ordene inspeccionar unos lugares, dos o tres, dónde cree que hay restos humanos. Estoy muy tenso, ante el tribunal. Temo que el juez le haga caso. Si lo hace descubrirá que soy culpable, de asesinar a alguien hace mucho tiempo. Pienso autoinculparme si el juez decide ordenar el levantamiento. Sé que ese anciano, que no sé quién es ya que no le veo el rostro, es el único que sabe mi secreto. Me despierto con angustia”.

"Quiero tener un hijo y me voy con un amigo dónde una mujer. Me pongo de rodillas y me meten, creo que mi amigo, una pomada fría por el culo como preparación para hacerme una inseminación artificial. De pronto me doy cuenta de lo absurdo de la situación y me voy diciéndole a la señora que no es posible que yo me quede embarazado”.

Fue bastante doloroso para el paciente darse cuenta de los sentimientos homoeróticos que tenía hacia su nieto, y que eran la base de su amor hacia él. Comprender el sentido de los mismos como desplazamiento del conflicto histórico, de la culpa inconsciente que eso le activaba, y que derivó, cuando su nieto tuvo el accidente, en la necesidad de un castigo que pudo poner en marcha elproceso canceroso en un tejido corporal que ya estaba deteriorado por el tabaco.

El contacto con esto le produjo un sufrimiento que no esperaba y casi mayor que el saber que tenía un cáncer. El análisis entró en un momento muy delicado pues prefería morir, "matando sus tendencias”, que hacer daño a su nieto.

El análisis podía continuarse centrándose en el meollo del material citado aún con el riesgo de una regresión somática por los sentimientos depresivos que reemergieron junto a una dejación

\footnotetext{
${ }^{7}$ Exceso de pensamiento positivo. Pensamiento idealizado propuesto como capacidad de transformación rápida de los conflictos. Los pensamientos negativos y las limitaciones que muchos sentimos en nuestra vida no tienen cabida en el corazón y en la mente de estas personas. A veces propuesto como capacidad de transformación rápida de los conflictos.
} 
de los cuidados necesarios. Ya no había riesgo de paralización del sistema inmunológico por lo que permanecer en lo depresivo podía activar material más profundo.

Esta etapa fue delicada también para mí, me preguntaba si "quizás sobrevaloré las posibilidades del paciente en el inicio, o las mías propias”, y tenía que poner una atención especial en la contratransferencia.

Intensificación del trabajo en la transferencia-contratransferencia. Teniendo en cuenta los materiales que pueden ser transferidos. 1) Las pulsiones amorosas (transferencia positiva) y agresivas (transferencia negativa). 2) Las defensas creadas para resolver el conflicto entre las demandas pulsionales e instintivas y el mundo frustrante. Entre ellas hacer mención especial al carácter y sus formas defensivas concretas. 3) Las formas de relación objetal internalizadas desde las muy primitivas a las más elaboradas. El "fin” de la pulsión no sería la satisfacción libidinal mediante un "objeto" sino la creación de una relación objetal. 4) Partes del self. 5) Complejos y arquetipos.

El estilo terapéutico está descrito más a fondo en mi capítulo Artes de mi oficio de analista integrativo (Garcia, 2008).

Afortunadamente la situación pudo movilizarse, y elaborarse una parte importante del material.

\section{Finalización. Muerte simbólica. Renacer}

Después de nueve meses acordamos el alta. Estaba asintomático. Había retomado un proyecto artístico que tenía desde hacía años y transformado la relación con el nieto de la que ya no dependía para nutrirse.

La limitación del tiempo del encuadre de nueve meses en el inicio tenía un reto simbólico. Evocar la metáfora de un proceso de embarazo que termina, seguro, en muerte a la fase intrauterina a la que le sigue otro tipo de vida. Además, el paciente había manifestado que nació a los 10 meses. Objetivamente es seguramente incorrecto. Plantear 9 meses para la terapia convoca lo simbólico de su percepción.

En mi contratransferencia final tenía sentimientos de satisfacción por el éxito del tratamiento y dolor por la pérdida de una buena y provechosa relación de ayuda.

Tres sesiones finales para trabajar varios aspectos: duelo de la separación; evaluación conjunta de los cambios producidos en ambos por el proceso; devolución diagnóstica (también de los cambios medidos por retest (MCMI Millon); exploración de los retos futuros; aspectos éticos de la relación que tuvimos; la sugerencia de que elaborara un relato mítico de su proceso; preparase para ser un agente de salud, de conciencia y de paz en su medio.

Para abordar la ética es útil trabajar con algún mito fundante de la moral como regulador social con un sentido dinámico. Que sea distinto de la mitología propia, de otra cultura, para aportar diversidad y contraste.

Este fue el que le propuse:

Zeus, apiadándose de los hombres (a los que Prometeo ya les había obsequiado el fuego, base del proceso técnico, pero carentes de capacidad política), repartió los fundamentos básicos de la moralidad: el aidos (pudor o vergüenza) y díke (sentido de la justicia) y Zeus encargó que a todos los humanos se les dotara de tales sentimientos:

"A todos, dijo Zeus, y que todos participen. Pues no existirían las ciudades si tan solo unos pocos de ellos lo tuvieran, como sucede con los saberes técnicos. Es más, dales de mi parte una ley: que a quien no sea capaz de participar de esta moralidad y de la justicia que lo eliminen como a una enfermedad de la ciudad”(Platón, 1990, p. 133). 
En una cultura en la que los idealismos convierten las mentiras en "formas de vida", el proceso de verdad depende de si hay personas que sean suficientemente agresivas y libres «desvergonzadas».

El proceso terapéutico te convierte potencialmente en un sujeto desvergonzado. Actuar la desvergüenza coloca al sujeto en una dimensión nueva de su praxis ética. Sus acciones pueden ser más performativas (Austin, 1971) y elegir o no esas acciones es un proceso de equilibrio entre expresar la "verdad” y la prudencia necesaria para no ser eliminado (Butler, 2006). Reflexionar sobre todo esto es importante antes del alta para elaborar las dificultades, miedos, que le surjan al paciente ante el renacer a lo social.

\section{Conclusiones}

Un proceso de psicoterapia con un paciente con cáncer requiere valorar muy fino si es posible o no poner en marcha un conjunto de herramientas principales y coadyuvantes para soportar un trabajo activo y movilizador en un tiempo breve, pues de ser factible el proceso podrá tener mejor pronóstico. Será complicado atender a varias convergencias: psicoterapia, medidas energéticas, los tratamientos oncológicos convencionales que el paciente elija, su sistema familiar y el sistema sanitario.

El nivel de intervención va a depender de si es posible formular una hipótesis psicodinámica inicial lo suficientemente plausible para explicar si el síntoma cáncer tiene un claro componente psicosomático, junto con otras variables de analizabilidad y de activación del arquetipo "sanador herido" en el terapeuta.

La psicoterapia necesita adaptarse a las condiciones diferenciales que el proceso del cáncer tiene respecto a otras situaciones clínicas. La presencia fáctica de la muerte moviliza en el paciente fuerzas regresivas y progresivas de un modo intenso, estas últimas activadas por fuerzas arquetípicas.

El objetivo no es la curación del cáncer sino la mayor calidad de vida, aceptando la muerte como compañera del viaje de la vida.

La articulación de herramientas psicoanalíticas, reichianas y junguianas aborda la complejidad del sujeto, y del proceso, de un modo que permite dinamizar profundamente las dimensiones humanas.

El trabajo va a tener un ritmo intenso y debe articularse con la potenciación de las defensas biológicas del sujeto. Será selectivo eligiendo tanto los focos de trabajo más apropiados del material como el nivel de profundización. Tendrá fases artesanas para ir articulando el caos, con un espíritu creativo que transforme el drama en resiliencia. Analizando resistencias, transferencia, potenciando la capacidad simbólica y una nueva narrativa mítica de su existencia.

El proceso cambia al paciente y al terapeuta. En el cese de la relación se hace un trabajo de elaboración de la relación entre ambos. Cuando es porque el paciente va a morir, se trabajan los diversos duelos de la muerte, las dimensiones transpersonales y el acompañamiento final para una muerte digna. Es la alta terapéutica por remisión del cáncer o por cumplir los objetivos terapéuticos conviene, además, elaborar la dimensión ética de la relación y su proyección en el futuro. 


\section{Bibliografía}

Abac, M. (2008). La personalidad velada. La sensualidad reprimida y la creación. México: Fata Morgana. Austin, J. L. (1971). Cómo Hacer Cosas con Palabras: Palabras y acciones. Buenos Aires: Paidós. Burke, K. (1969). A Grammar of Motives. Berkeley: University of California Press.

Butler, J. (2006). Vida precaria: el poder del duelo y la violencia. Buenos Aires: Paidós.

Castillo, J. (2017). Psicoterapia de orientación junguiana. Una perspectiva integrativa de la psicología analítica. Madrid: Prismática.

Chiozza, L. (1989). Psicoanálisis de los trastornos hepáticos. Buenos Aires.: Edic. del C.I.M.P.

Davanloo, H. (1992). Psicoterapia breve. Madrid: Dorsa.

Foucault, M. (1976). Vigilar y castigar. México, Siglo XXI.

Garcia, M. (2008). Artes de mi oficio de analista integrativo. En Cómo Psicoanalizamos. De cómo la psicoterapia aborda el padecer humano (J. Castillo y R. Guerra eds.). Madrid: Manuscritos.

Grof, S. (1994a). La evolución de la conciencia. Barcelona: Kairós.

Grof, S. (1994b). Psicología transpersonal: nacimiento, muerte y trascendencia en psicoterapia. Barcelona: Kairós.

Jung, C. G. (1990). Sincronicidad. Málaga: Sirio.

Jung, C. G. (1993). La psicología de la transferencia. Barcelona: Paidós.

Jung, C. G. (1994). Tipos psicológicos. Barcelona: Edhasa.

Jung, C. G. (2001). La lucha con la sombra. En Civilización en transición. (Obra completa, Vol. 10).

Madrid: Trotta.

Jung, C. G. (2004). La función Transcendente. En La dinámica de lo inconsciente (Obra completa). Madrid:

Trotta.

Jung, C. G. (2005). Psicología y Alquimia. (Obra completa, Vol. 12). Madrid: Trotta.

Navarro, F. (1993). Metodología de la vegetoterapia-carateroanalítica. Valencia: Orgón.

Navarro, F. (1998). La somatopsicodinámica. Valencia: Orgón.

Peat, D. (1988). Sincronicidad. Barcelona: Kairós.

Platón. (1990). Protágoras. (Carlos García Gual, Trad.). Madrid: Gredos.

Reich, W. (1942). La biopatía del cáncer. Buenos Aires: Nueva Visión (1985).

Salman, S. (1993). Response: Fermenting the Dialectic into Psychological Process. En Mary Ann Mattoon (Ed.), The Transcendent Function: Individual and Collective Aspects: Proceedings of the Twelfth International Congress for Analytical Psychology. Einsiedeln: Daimon Verlag.

Sennet, R. (1997). Carne y piedra. El cuerpo y la ciudad en la sociedad occidental. Madrid: Alianza.

Strachey, J. (1976). The Evolution of Psychoanalytic Technique. Nueva York: Basic Books.

Von Franz, M. L. (1989). Alchimie et Imagination active. París: Éditions Jacqueline Renard.

Von Franz, M. L. (1991). Alquimia. Barcelona: Luciérnaga. 